\title{
Cidade e cinema: diálogos sobre questões de moradia e corpografias urbanas
}

\section{City and cinema: dialogues on housing issues and urban corpographs}

\section{Ciudad y cine: diálogos sobre problemas de vivienda y corpografías urbanas}

Matheus Guimarães Costa

Universidade Estadual de Feira de Santana

\section{1}

iD (9) Alex Santana França

Universidade Estadual de Feira de Santana

Resumo: Tomando como ponto de partida a utilização do cinema como potente ferramenta de transformação, e linguagem que propicia espaços de discussão e aprendizado, o presente relato propõe-se compartilhar experiências resultantes do cinedebate com o tema "Direito à cidade e território no Brasil", promovido pelo projeto de extensão Cinema: subjetividade, cultura e poder, da Universidade Estadual de Feira de Santana, no intuito de trazer à pauta as lutas por moradia e o quanto os corpos que habitam o espaço urbano são afetados pelas dinâmicas sociopolíticas que os atravessam. O filme escolhido para exibição e debate foi o documentário Leva (2011), dirigido por Juliana Vicente e Luiza Marques, que aborda a temática citada. A partir da atividade realizada, foi 
possível refletir não só sobre a experiência urbana em São Paulo, no que se refere às reivindicações pelo direito à cidade e à moradia, mas analisar a própria realidade local baiana, e mais especificamente, a da cidade de Salvador.

Palavras-chave: Extensão universitária. Cinedebate. Documentário. Direito à moradia.

Abstract: Taking as a starting point the use of cinema as a transformation tool, and language that provides spaces for discussion and learning, this report proposes to share experiences resulting from the cinema debate with the theme "Right to the city and territory in Brazil", promoted by the extension project "Cinema: subjectivity, culture and power" from the State University of Feira de Santana, in order to bring to the agenda the struggles for housing and how much the bodies that inhabit the urban space are affected by the

2 socio-political dynamics that cross them. The film chosen for exhibition and debate was the documentary Leva (2011), directed by Juliana Vicente and Luiza Marques, that addresses the aforementioned theme. From the activity carried out, it was possible to reflect not only on the urban experience in São Paulo, with regard to the claims for the right to the city and housing, but to analyze the local reality of Bahia, and more specifically, that of the city of Salvador. Key-words: University Extension. Cinedebate. Documentary. Right to housing.

Resumen: Tomando como punto de partida el uso del cine como una herramienta de transformación y lenguaje que brinda espacios de discusión y aprendizaje, este informe propone compartir experiencias resultantes del cinedebate con el tema "Derecho a la ciudad y al territorio en Brasil", impulsado por el proyecto de extensión Cine: subjetividad, cultura y poder de la Universidad Es- 
tadual de Feira de Santana, con el fin de traer a la agenda las luchas por la vivienda y cuánto los cuerpos que habitan el espacio urbano se ven afectados por las dinámicas sociopolíticas que las atraviesan. La película elegida para exhibición y debate fue el documental Leva (2011), dirigido por Juliana Vicente y Luiza Marques, que aborda el tema mencionado. A partir de la actividad realizada, fue posible reflexionar no solo sobre la experiencia urbana en São Paulo, en cuanto a las reivindicaciones del derecho a la ciudad y a la vivienda, sino analizar la realidad local de la propia Bahía y más específicamente, de Salvador.

Palabras clave: Extensión Universitaria. Cinedebate. Documental. Derecho a la vivienda.

Data de submissão: 20/11/2020

3

Data de aprovação: 16/12/2020 
Cidade e cinema: diálogos sobre questões de moradia e corpografias urbanas Matheus Guimarães Costa • Alex Santana França

O cinema, assim como qualquer forma de arte, pode ser tomado como ponto inicial para pensar os atravessamentos que constituem as relações que se estabelecem nos espaços diversos. Diante disso, o presente relato tem o objetivo de compartilhar a experiência do cinedebate, com o tema "Direito à cidade e território no Brasil", realizado no dia 24 de julho de 2020, sob a minha organização, e desenvolvido pelo projeto de extensão "Cinema: subjetividade, cultura e poder", vinculado à Universidade Estadual de Feira de Santana, e com a coordenação geral da Prof. Dra. Ivone Maia de Mello, que objetiva investigar a relação entre o cinema e os processos de subjetivação com ênfase nas formas contemporâneas de sofrimento psíquico, em uma perspectiva social (MELLO, 2011). Entre as atividades realizadas por esse projeto, destaca-se o Sala de Cinema UEFS, que promove a exibição e debate de filmes para estudantes, professores, funcionários da universidade e comunidade externa, de caráter presencial, mas que desde março de 2020, frente aos impactos do COVID-19, têm se realizado no ambiente virtual, através de encontros on-line no Google Meet, o que ampliou a participação e colaboração de pessoas oriundas de diferentes lugares do país, e possibilitou um maior intercâmbio de saberes e vivências de várias realidades distintas.

De uma maneira geral, os debates promovidos pelo projeto também têm transitado por diversas áreas do conhecimento e percorrido significativas discussões acadêmicas, com grande potencial de gerar maior criticidade e possibilitar novas posturas perante a sociedade. Aos participantes da atividade é oferecida a alternativa de buscar conhecimento por outros meios, além do método didático-expositivo, facilitando as diversas reflexões que favorecem o processo ensino-aprendizagem, acentuando a característica do cinema como também uma ferramenta possível para acessar múltiplos conhecimentos. 
Cidade e cinema: diálogos sobre questões de moradia e corpografias urbanas Matheus Guimarães Costa • Alex Santana França

Assim, através da promoção de debates com base em produções fílmicas, essa proposta insere-se satisfatoriamente na ação extensionista, a partir do momento em que se coloca para a elaboração de um espaço de troca e diálogo com a comunidade acadêmica e externa e objetiva possibilitar transformações possíveis nos diversos contextos atravessados. Segundo essa perspectiva, a extensão universitária, aliada ao ensino e à pesquisa, passa a contribuir mais significativamente para minimizar as demandas sociais que exigem da universidade novas diretrizes no início do século XXI. De acordo com Serrano (SERRANO, 2006), em diálogo com texto "Extensão ou Comunicação", de Paulo Freire, o conhecimento, quando transmitido e não construído pelos partícipes da ação, caracteriza uma relação verticalizada, ou seja:

5

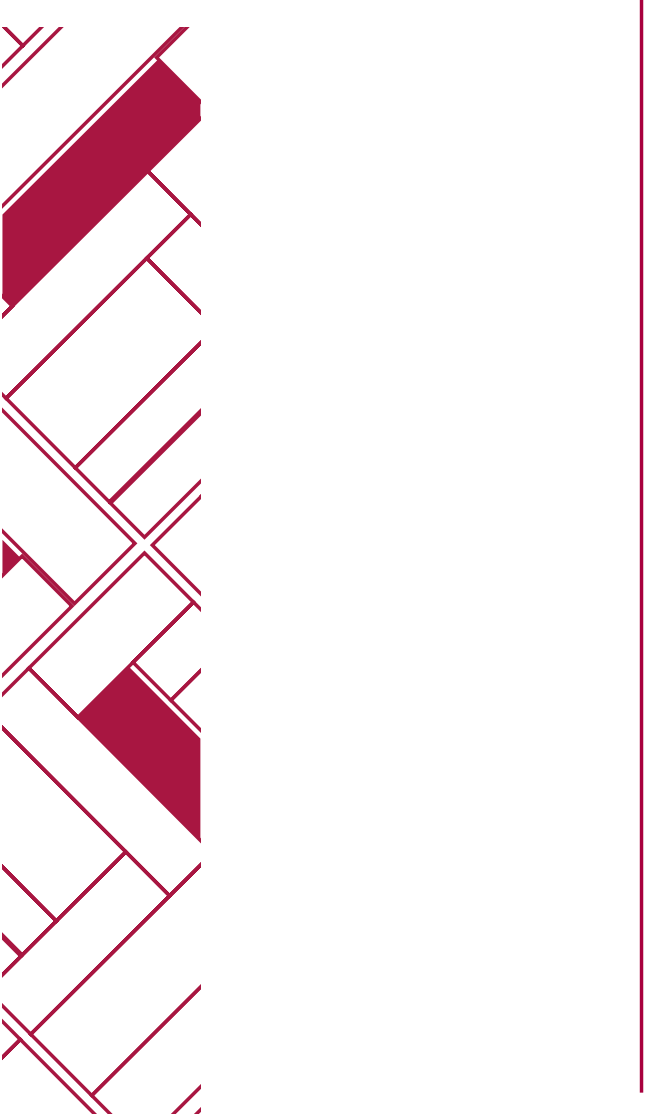

Parte do pressuposto de que há uma superioridade e messianismo de quem estende, que escolhe o que transmitir, como transmitir e que desconhece a visão de mundo dos que vão receber, e estes passam a ser sujeitos passivos no processo. Freire nos dirá que: "todos estes termos envolvem ações que, transformando o homem em quase "coisa" o negam como um ser de transformação do mundo" (2006:22); ou ainda nos questionará sobre o ato de conhecer e o papel do educador; afirmando que o conhecimento só se materializa como tal, na medida em que for apreendido e aplicado à realidade concreta. Ao desconhecer a cultura da população a quem se destina, esta extensão é antidialógica e manipuladora. Freire nos propõe a quebra da verticalidade "coisificadora" onde um ator é sujeito e o outro objeto, para uma relação onde todos possam ser sujeitos atuantes, que agem e pensam criticamente. (SERRANO, 2006, p. 3-4) 
Cidade e cinema: diálogos sobre questões de moradia e corpografias urbanas Matheus Guimarães Costa • Alex Santana França

Para romper com essa visão questionada por Freire e buscando construir uma abordagem horizontal na experiência de extensão universitária, torna-se imprescindível que a realidade discutida nos debates proporcionados pela equipe do projeto conte com a presença de teóricos, estudiosos na área, ou pessoas que tenham vivências em torno dos temas abordados. Assim, referente ao cinedebate com o tema "Direito à cidade e território no Brasil", assunto de relevante interesse para mim como estudante de graduação em Engenharia Civil, foi sugerido o filme Leva (2011), produção da Preta Portê Filmes e do Canal Futura, dirigida por Juliana Vicente e Luiza Marques, que revela como vivem as pessoas que moram em ocupações no centro da capital paulista e de que forma os movimentos por moradia se organizam. “No coração de São Paulo pulsa o maior movimento de luta por moradia da América Latina", diz a sinopse. O documentário apresenta entrevistas com representantes da Frente de Luta por Moradia (FLM), do Movimento dos Sem Teto do Centro (MSTC), do Movimento por Moradia Região Centro (MMRC), entre outros, mostra a luta pelo direito de morar no centro da cidade, e a transformação dos espaços abandonados pelas mãos dos moradores, em um esforço coletivo e orquestrado.

Para ampliar o debate sobre o assunto, foram convidadas Thaianna de Souza Valverde, Mestra em Planejamento Urbano e Regional pela Universidade Federal do Rio de Janeiro (IPPUR/UFRJ), Professora do Curso de Direito da Universidade Católica do Salvador (UCSAL) e Assessora da equipe urbana do Centro de Estudos e Ação Social (CEAS), e Julia de Andrade, graduanda em Direito na UCSAL, pesquisadora do Centro de Educação em Direitos Humanos (CEDH), com ênfase em direito à cidade, que compartilharam seus estudos em torno das dinâmicas que permeiam os ambientes urbanos e abordaram um pouco mais da realidade de Salva- 
Cidade e cinema: diálogos sobre questões de moradia e corpografias urbanas Matheus Guimarães Costa • Alex Santana França

dor, em comparação às movimentações das lutas no contexto da cidade de São Paulo apresentadas no documentário.

Como a obra indicada comprova, a cidade carrega histórias e um acervo de repertórios diversos nas subjetividades que a compõem. Dentro das movimentações que as soberanias professam, é quase que institucionalizado normalizar a guerra como uma forma de exercer o direito de matar, pensando que matar ou deixar viver constituem os limites da soberania (MBEMBE, 2003, p.5), por isso pensar a cidade urbana contemporânea, através do olhar para os corpos que habitam esse espaço, para as violências que se reverberam pelos ecos coloniais das estruturas que compõem o território analisado, pensando principalmente que lugar é dado à vida, à morte e ao corpo marginalizado ou ferido, e em qual ordem de poder se expressam essas dinâmicas, tornam-se essenciais.

\section{7}

\section{Disputa por Espaço na Cidade e as Corpografias Ur- banas a Partir do Documentário Leva}

Diante das dinâmicas que atravessam a cidade urbana na contemporaneidade, a atividade promovida exigiu a utilização de um repertório conceitual que compreendesse essas complexidades sem superficializar as relações que se cruzam nesse espaço. Existe uma multiplicidade de elementos heterogêneos que se cruzam, cada um com suas especificidades, velocidades e estruturas baseadas em um passado não longínquo, que ditam a ocupação dos espaços, acessos e movimentações. Mais do que portadoras de infraestruturas físicas e materiais, a cidade é a sobreposição de relações, funções (produtivas, políticas, disciplinares e simbólicas, escalas (espaciais e temporais/geográficas e históricas), fluxos, territórios e territorialidades (GAIA, 2010). 
Cidade e cinema: diálogos sobre questões de moradia e corpografias urbanas Matheus Guimarães Costa • Alex Santana França

Exemplo disso está na estreita relação entre corpo e cidade, visto que, para a cidade realizar suas condições interativas, ela depende das movimentações que os corpos que compõem esse espaço possuem, usando da sua força motora para gerar essas dinâmicas. Nesse sentido, a nomenclatura "corpografia urbana", trazida por Britto e Jaccques (2008, p. 79), que se refere a um tipo de cartografia realizada pelo e no corpo, ou seja, a memória urbana inscrita no corpo, o registro de sua experiência da cidade, uma espécie de grafia urbana, que configura o corpo de quem a experimenta, foi adotada nesse trabalho. Entretanto, o modelo de produção capitalista, ao qual os centros urbanos estão submetidos, afeta radicalmente essa relação, que costuma ser apoiada na exploração/ dominação de indivíduos, seguindo também uma ordem de poder. Costa e Azevedo (2016, p. 2), inclusive, analisam como se deu a ocupação do solo urbano no país por ex-escravizados e escravizadas e discorrem sobre a não efetivação das leis abolicionistas na história do Brasil, uma vez que após a abolição inacabada, esse segmento populacional não teve acesso a um local propício para morar, restando-lhe ocupar outros espaços:

Desde a época da colonização do Brasil por Portugal e após o fracasso em escravizar totalmente a população indígena precedente no país, os portugueses passaram a trazer para - Brasil, negros e negras africanos para trabalhar de forma escrava na colônia. Com o passar do tempo e as mudanças econômicas, a Inglaterra, que exportava produtos ingleses para o Brasil, percebeu que para aumentar seu comércio era necessário que mais pessoas brasileiras pudessem comprar. Dessa forma, passou a pleitear perante as autoridades luso-brasileiras, a libertação dos (as) escravos (as) para que assim os mesmo pudessem se tornar 
Cidade e cinema: diálogos sobre questões de moradia e corpografias urbanas Matheus Guimarães Costa • Alex Santana França

consumidores e assim aumentar o mercado inglês. (COSTA; AZEVEDO, 2016, p.2)

Ainda nesse período, mais especificamente em 1850, foi aprovada a Lei de Terras, que dispôs normas sobre a venda, a posse e a utilização de terras a partir do Segundo Reinado. Ela foi criada como uma resposta da elite agrária brasileira para os escravizados e seus descendentes que acreditavam que iriam poder acessar todos os direitos de cidadãos brasileiros, inclusive o direito à terra, com a liberdade. Para manter a concentração agrária nas mãos de poucos, tornando a compra/venda única forma para o acesso à terra, que passou a assumir o status de propriedade privada, essa lei, que favoreceu apenas os grandes proprietários rurais, caracterizou-se como mais uma medida prática para manter as condições exploratórias sobre corpos negros. Em resposta ao questionamento "Qual o sentido político da abolição, destituída de medidas que mudassem a realidade da população negra?", proposto pelas autoras acima citadas, a conclusão da qual diferentes fontes historiográficas chegam, a exemplo do documentário, é que restou aos ex escravizados e seus descendentes disputarem o ambiente urbano por outras vias.

Com o notório desenvolvimento das grandes cidades brasileiras, ao longo do século XX, diferentes espaços urbanos passaram a possuir cor e classe social. Os bairros centrais passaram a ter valores financeiros altíssimos, em contrapartida com os bairros periféricos, que eram ocupados ilegalmente. Como afirma Martins (2003, p.69), "a cultura negra é, epistemologicamente, o lugar das encruzilhadas, onde a própria noção de centro se dissemina". Sabendo que é no centro que há a disputa por condições de cada indivíduo de usufruir desse espaço urbano, e tomando conhecimento que a história brasileira é marcada pela colonialidade e 
Cidade e cinema: diálogos sobre questões de moradia e corpografias urbanas Matheus Guimarães Costa • Alex Santana França

descontinuidades de direitos, principalmente dos povos negros e originários, se faz essencial, tomando a cidade também como terreno de investigação, repensar o espaço das cidades, já que ainda hoje essas violências se reverberam nas dinâmicas que tocam esse território. Estudos sobre o crescimento da cidade de São Paulo, por exemplo, de acordo com Carril (2006, p.17), mostram "como a população ficava mais escura à medida em que se afastava em direção à periferia".

Segundo Tone (2015), a produção do espaço da cidade pode ser descrita pela sequência de três camadas, a primeira corresponde à transformação da terra em propriedade (imobiliária), a segunda passa pela legalização dos lotes, a partir dos processos de anistia e mobilização da infra-estrutura até estes, mediante mobilização e reivindicação dos próprios moradores, provisão com redes hidrossanitárias, luz, pavimentação; então os lotes passam a sofrer taxação pelo governo, expulsando os moradores "primeiros", confeccionando a ideia de margem, enquanto espaços habitados com condições estruturais subdesenvolvidas, como exemplo de muitos espaços periféricos (TONE, 2015). Entretanto, a cidade, mais do que um local de produção e consumo de mercadorias e de habitação, é também um importante lócus da vivência humana em sua dimensão plena, e seu espaço reflete e condiciona as diversas estratégias engendradas pelos diferentes agentes sociais na criação e apropriação da riqueza (produção e comercialização de mercadorias), da reprodução da força de trabalho e do desenrolar da vida cotidiana como um todo, educação, consumo, atividades culturais, lazer. Nascimento e Matias (2011), inclusive, trazem um estudo sobre a produção de espaços urbanos, tomando como parâmetro a cidade de Ponta Grossa, Paraná, mas que reflete a história da organização espacial de muitos outros centros urbanos brasileiros: 
Cidade e cinema: diálogos sobre questões de moradia e corpografias urbanas Matheus Guimarães Costa • Alex Santana França

A importância da terra urbana enquanto condição essencial para a realização de qualquer atividade, somada ainda às suas propriedades intrínsecas (sobretudo amenidades físicas), confere a ela o caráter de mercadoria, assumindo assim um determinado preço a ser pago pelos indivíduos desprovidos do direito de propriedade privada. Enquanto simples matéria, elemento da natureza, a terra não possui valor, pois não pode ser reproduzida pelo trabalho humano. Todavia, enquanto componente do espaço geográfico, a terra transcende a condição de mera superfície, sítio das edificações, e agrega atributos específicos que viabilizarão, em maior ou menor grau, as necessidades de produção e consumo no espaço urbano (...) Em função disso, pode-se dizer que a terra urbana assume a condição de "terra mercadoria", apresentando um valor de uso, dado pela sua condição de elemento vital, não reprodutível e indispensável à atividade humana, além de um valor de troca, pois diante da demanda e da possibilidade iminente de acumulação de riqueza que a mesma representa a quem tenha sua posse, assume um preço. (NASCIMENTO; MATIAS, 2011, p. 5)

Nesse direcionamento de pensar a cidade como lugar de disputa, não só pelo espaço em si, mas por tudo que ele agrega no dia a dia de quem a habita, acesso ao trabalho, facilidade na mobilidade de um ponto a outro, hospitais, mercados e farmácias, consequentemente a localização aparece como principal valor de um determinado fragmento do espaço urbano em virtude das vantagens que a mesma pode proporcionar na realização das atividades econômicas ou à função residencial. Para as empresas, a disponibilidade de localizações favoráveis é fundamental para usufruir 
Cidade e cinema: diálogos sobre questões de moradia e corpografias urbanas Matheus Guimarães Costa • Alex Santana França

das vantagens de aglomeração, como o acesso aos principais mercados consumidores, proximidade a atividades complementares e - principalmente para as indústrias - condições adequadas para o transporte de mercadorias.

A partir disso é possível compreender que há uma luta por moradia no âmbito urbano, visto que o centro, como espaço provedor de "facilitações" diversas para o indivíduo/empresa, vai ser palco de lutas por ocupação e cada infraestrutura que compõe esse território central deverá então, exercer sua função social. A propriedade compreende, em seu conteúdo e alcance, para além do tradicional direito de uso, gozo e disposição por parte de seu titular (direito-garantia), a obrigatoriedade do atendimento de sua função social, cuja definição é inseparável do requisito obrigatório do uso racional da propriedade e dos recursos ambientais que the são integrantes. O proprietário (pessoa física ou jurídica, de direito público ou privado), como membro integrante da comunidade, se sujeita a obrigações crescentes que, ultrapassando os limites do direito de vizinhança no âmbito do direito privado, abrange o campo dos direitos da coletividade, visando o bem-estar geral, no âmbito do direito público (JELINEK, 2006).

Através do documentário Leva é possível acompanhar a vida de moradores da ocupação do edifício Mauá, um dentre muitos ocupados no centro da cidade de São Paulo, com base nos depoimentos de pessoas oriundas de diversas regiões do Brasil, que por motivos variados migraram para a capital paulista em busca de melhores condições financeiras e habitacionais, assim como revela a organização de uma mobilização popular comandada por movimentos, como o Associação Sem-Teto do Centro de São Paulo (ASTC-SP), o Movimento dos Sem Teto do Centro (MSTC) e o Movimento por Moradia Região Centro (MMRC), que se unem para transformar os espaços abandonados em habitáveis. 
Cidade e cinema: diálogos sobre questões de moradia e corpografias urbanas Matheus Guimarães Costa • Alex Santana França

Em um dos relatos, um integrante do edifício, trazendo suas vivências sobre as relações de trabalho nesse espaço urbano, diz ter "nojo de patrão". Essa fala em específico, logo no início do filme, traz um pouco do quanto essa posição de dono/proprietário/empresário é opressora, visto que se coloca como agente garantidor de manutenção das violências urbanas, porque possui propriedades nas regiões centrais, usufruindo das facilidades que essa localização fornece, e usa disso a seu favor, ao expulsar pessoas para as periferias, subalternizando seus corpos e relativizando suas necessidades.

Outras falas discorrem a respeito das dificuldades de chegar ao trabalho, devido às deficiências nas dinâmicas da mobilidade urbana. Para as populações que ocupam locais periféricos, as distâncias físicas são grandes em relação ao centro, logo são necessárias ferramentas para que esses indivíduos se locomovam mais rapidamente a seus locais de trabalho. Há um outro relato no qual o narrador afirmou não receber do patrão vale transporte, utilizando praticamente todo seu salário para pagar aluguel e condução.

Em um segundo momento do documentário, após relatarem suas trajetórias e dificuldades até chegarem aos movimentos populares por moradia, os depoentes começam a contar a organização da ocupação do edifício, as divisões do trabalho e os enfrentamentos diversos que atravessam seus posicionamentos. Constam ainda depoimentos de algumas pessoas que integram a coordenação de alguns desses grupos, e como eles se articularam a partir de um propósito unificado, o de construir espaços de debate e mobilizações para repensar o espaço urbano e reivindicar a cidadania como um processo de educação sistemática, através do esforço coletivo pelo aproveitamento do espaço urbano que não exerce sua função social.

O filme, que por se restringir à realidade de São Paulo, não caracteriza as narrativas diversas que integram os inúmeros cen- 
Cidade e cinema: diálogos sobre questões de moradia e corpografias urbanas Matheus Guimarães Costa • Alex Santana França

tros urbanos do Brasil, o que revelou a necessidade de trazer para o debate as dimensões das lutas por moradia e dinâmicas urbanas na Bahia, mais especificamente em Salvador, capital do Estado e cidade mais desenvolvida da região. Assim, as convidadas que integraram o espaço de conversa proposto trouxeram para o debate suas vivências e estudos sobre o direito à cidade.

Em sua fala, a pesquisadora Julia de Andrade, por exemplo, apresentou alguns pontos que foram centelhas potentes na discussão sobre o tema proposto para o evento. Ela tratou da questão da gentrificação no centro de Salvador, um dos elementos recorrentes no processo permanente de (re)estruturação urbana. Processo esse que é parte da organização do espaço urbano, de acordo com as necessidades do modo de produção dominante na economia e que está em sintonia com os propósitos da estrutura dominante da sociedade em um período histórico determinado (FURTADO, 2014). No intuito de ilustrar essa situação, a convidada mencionou o Projeto Revitalizar, desenvolvido pela prefeitura de Salvador, com o pretexto de reorganizar a área central da cidade (bairros do Centro, Centro Histórico, Santo Antônio, Comércio, Saúde, Nazaré, Tororó, Barris, Barbalho, Lapinha e, parcialmente, a Liberdade). Ele estabelece que imóveis com débitos em tributos, desocupados e sem manutenção podem ser desapropriados pela prefeitura. Suas principais motivações estão ligadas ao interesse privado e relacionadas com a especulação imobiliária, por isso ele é uma tentativa de elitização do Centro Antigo para atender aos turistas e o empresariado, não levando em conta a função social da cidade e da propriedade. Moradores, lideranças políticas e militantes do movimento de moradia entendem isso como meio de gentrificação do Centro Antigo da cidade.

Assim, no caso de Salvador, a Administração pública conseguiu restaurar grande parte do complexo arquitetônico de Pelou- 
Cidade e cinema: diálogos sobre questões de moradia e corpografias urbanas Matheus Guimarães Costa • Alex Santana França

rinho, mas a que preço? Enquanto os proprietários, comerciantes e turistas foram valorizados, a população local mais uma vez foi prejudicada. Logo é possível traçar um paralelo entre Salvador, através da gentrificação do Pelourinho, influenciada pelo potencial turístico e pela história colonial que marca esse território, e São Paulo, palco de dinâmicas econômicas intensas, que causam disputas pelos indivíduos que ocupam locais diversos, convergindo classe social, raça e gênero.

O debate que foi construído, a partir de uma produção audiovisual, foi potente na discussão dos temas que atravessam as questões de moradia na cidade, visto que foi possível relacionar com áreas diversas, como Direito, Engenharia Civil, Arquitetura e Psicologia, já que a atividade contou com a presença de profissionais de todas as áreas do conhecimento citadas, trazendo suas visões a partir de diversos locais, possibilitando pensar como que as infraestruturas urbanas têm afetado os corpos que disputam esse espaço, como suas subjetividades são atingidas e quais elementos históricos têm contribuído para essas conformações. Dentre os inscritos no evento, muitos discentes e docentes da UEFS, e dentre os inscritos da comunidade externa houve uma variedade enorme de coletivos que eles integram, tiveram pessoas da Universidade Católica de Salvador, Aluno de Psicologia na Universidade Salvador (UNIFACS), da Universidade Federal da Bahia, Universidade Estadual de Goiás, Brigada de Arquitetura e Urbanismo do MTST, Universidade do Estado da Bahia, Partido Comunista Brasileiro, Universidade Federal de Santa Catarina, Greenpeace Salvador, Universidade Federal de Sergipe e Universidade Federal do Ceará, mostrando o quanto o público foi diverso e pôde contribuir com bagagens importantes para a construção desses diálogos que traçamos em torno das questões de moradia a partir de diversos locais acadêmicos e de luta no Brasil. 
Cidade e cinema: diálogos sobre questões de moradia e corpografias urbanas Matheus Guimarães Costa • Alex Santana França

\section{Considerações Finais}

A atividade de extensão universitária realizada e descrita nesse relato foi importante demais para minha formação enquanto estudante de graduação de Engenharia Civil, visto que o curso integra discussões sobre planejamento urbano, dinâmicas territoriais e movimentações imobiliárias, então, construir um espaço de discussão, tomando como ponto primordial as interseccionalidades que atravessam esse espaço urbano, se fez imprescindível.

O cinema e a arquitetura são campos que se utilizam das representações visuais para a construção de imagens/estruturas que trazem um significado para a formação de espaços/discussões diversos. Logo, ao debater sobre infraestruturas de dominação e de disputa, a partir de uma produção fílmica conectada com o espaço urbano, permitiu uma interdisciplinaridade que agregou bastante a formação pedagógica dos participantes dentro do para além do processo educativo que a universidade proporciona. Inclusive, existe uma variedade enorme de filmes documentários e curtas-metragens que tratam das questões urbanas e das implicações nas comunidades que se estabelecem nesses espaços, por isso, é possível pensar na continuidade de ações semelhantes a que foi promovida no cinedebate relatado, fabulando futuros possíveis a partir do cinema e tomando as trajetória e experiências de grupos sociais minoritários como centralidade das narrativas.

Nesse sentido, entre as ações futuras a serem desenvolvidas pelo projeto, inclui-se a efetivação de um plano de trabalho submetido por mim, já aprovado e cadastrado pela Pró-reitoria de Extensão Universitária, a ser orientado pelo Professor Doutor Alex França, do Departamento de Educação da UEFS, e um dos coordenadores do projeto de extensão, cujo título é “Relações de trabalho, educação e subjetividade no cinema a partir de uma perspectiva 
Cidade e cinema: diálogos sobre questões de moradia e corpografias urbanas Matheus Guimarães Costa • Alex Santana França

decolonial", que se propõe analisar como as relações econômicas produtivas são elementos que influenciam a construção da cidade e estão diretamente relacionadas com as opressões que afetam as pessoas que habitam e disputam por esse território, utilizando o cinema como ferramenta que permite a construção de espaços de debate e troca e de transformação social.

\section{Referências}

Britto, Fabiana Dutra; JacQues, Paola Berentein. Cenografias e CORPOGRAFIAS URBANAS: UM DIÁLOGO SOBRE AS RELAÇÕES ENTRE CORPO E CIDADE. DISPONIVEL EM: HTTPS://PORTALSEER.UFBA.BR/INDEX.PHP/PPGAU/ARTICLE/ VIEW/2648/1871. AcesSO EM: 18 OUt. 2020.

CARRIL, LouRdes. Quilombo, favela e PeRIFERIA: a Longa busCA da CIDADAnia. São Paulo: Annablume; Fapesp, 2006.

COSTA, Duane Brasll; Azevedo, Ully de Castro. 2016. Das senzalas Às FAVELAS: POR ONDE VIVE A POPULAÇÃO NEGRA BRASILEIRA. DisPonível EM: HTTPS://WWW.FVJ.BR/REVISTA/WP-CONTENT/UPLOADS/2016/07/SOCIALIZANDo_2016_12.PDF. ACESSO EM: 5 Nov. 2020.

Furtado, Carlos Ribeiro. São Paulo, 2014. Intervenção do Estado e (RE)estruturação uRbana: UM ESTUdo SObRE GENTRIFICAÇÃo. Disponível EM: INTERVENÇÃo do Estado E (RE)ESTRUtURAÇão URBANA. UM ESTUdo SOBRE GENTRI-FICAÇÃo. ACESSO EM: 25 OUT. 2020.

GaiA, Gabriela Leandro Pereira. Escapes possíveis na produção da cidade. DISPONIVEL EM: HTTPS://ISSUU.COM/GABRIELAGAIA/DOCS/ESCAPES_POSS_VEIS_NA_ PRODU_O_DA_CIDADE_. ACESSO EM: 18 OUT. 2020. 
Cidade e cinema: diálogos sobre questões de moradia e corpografias urbanas Matheus Guimarães Costa • Alex Santana França

JELINEK, ROCHELLE. O PRINCíPIO DA FUnção SOCIAL DA PROPRIEDADE E SUA repercussão sobre o sistema do Código Civil. Porto Alegre, 2006. DisPONIVEL EM: HTTPS://WWW.MPRS.MP.BR/MEDIA/AREAS/URBANISTICO/ARQUIVOS/ROCHELLE.PDF. ACESSO EM: 25 OUt. 2020.

LeVA. Direção: Juliana Vicente e Luiza Marques. Produção: Preta Portê Filmes. Coprodução: Canal Brasil. Brasil, 2011. 55 min. Formato HD.

MARTinS, Lêda. Performances da Oralitura - corpo, lugar da MEMÓRIA. 2003. DISPONÍVEL EM: HTTPS://PERIODICOS.UFSM.BR/LETRAS/ARTICLE/ VIEW/11881/7308. ACESSO EM: 25 OUT. 2020.

MBEMBE, Achille. Necropolítica. 2016. Disponível em: https://ReVistas. UFRJ.BR/INDEX.PHP/AE/ARTICLE/VIEW/8993/7169. ACESSO EM: 13 NOV. 2020.

Mello, Ivone Maia de. Anexo II - Apresentação do Projeto de extensão Sala de Cinema: subjetividade, cultura e poder. 2011.

NASCIMENTO, Ederson; MATIAS, Lindon FonseCA. Expansão urbana E DESIGUALDADE SOCIOESPACIAL: UMA ANÁLISE DA CIDADE DE PONTA GROSSA (PR). PARANÁ, 2011.

TONE, Beatriz Bezerra. Século XXI: valorizaçÃo imobiliária e DisSOluÇÃo URBANA. São PAUlo, 2015.

Serrano, Rossana Maria Souto Maior. Conceitos de extensão univerSITÁRIA: UM DIÁLOGO COM PAULO FREIRE. DISPONIVEL EM: HTTPS://WWW.ETS. UFPB.BR/PDF/2013/1\%20UNIVERSIDADE\%20E\%20SOCIEDADE/US\%2013_ TeXto\%201\%20SerRano_Conceitos\%20de\%20eXtensaO\%20universitaria. PDF. ACESSO EM: 12 OUT. 2020. 